\title{
Nutri Cereal Pearlmillet: Way Forward
}

\author{
Nirupma Singh ${ }^{1}$, S.P. Singh ${ }^{1}$, Manoj Kumar ${ }^{2}$, Krishan Kanhiya ${ }^{1}$ and Arvind Kumar ${ }^{\text {* }}$ \\ ${ }^{1}$ Division of Genetics, ICAR-IARI, New Delhi, India \\ ${ }^{2}$ ICAR-AICRP on Pearlmillet, Agriculture University (Jodhpur), India
}

*Corresponding author

\begin{tabular}{|c|c|}
\hline \multicolumn{2}{|r|}{ A B S T R A C T } \\
\hline & \multirow{6}{*}{$\begin{array}{l}\text { Pearl millet is the most important food crop in area and production after paddy and wheat } \\
\text { in India with more than } 90 \% \text { of the total pearl millet production of world. It is a staple food } \\
\text { for poor and small farmers and also source of livestock feed and fodder in the rainfed } \\
\text { regions of the country. It is highly resistant to high temperature, adaptable to poor soil, low } \\
\text { vulnerability to disease, insect-pests and has good nutritive value. Its tolerance to drought, } \\
\text { heat and soil salinity and its high water use efficiency makes it a climate smart crop. With } \\
\text { its high protein and mineral content (especially iron and zinc), high dietary fibre, gluten- } \\
\text { free protein and amazing health benefits makes it a nutri-cereal. Despite being nutrient } \\
\text { dense its use is limited due to rancidity and off-odour during storage. Pearl millet grains } \\
\text { contain a higher amount of lipids than any other cereals. High fat content with highly } \\
\text { active lipases causes hydrolysis of fats to fatty acids causing bitter and mousy odour. This } \\
\text { hinders the commercialization of nutri-cereal pearl millet. Exploring the relationship } \\
\text { between grain contents and different mechanisms of rancidity with their determinants } \\
\text { would be helpful in development of a rancidity free pearl millet hybrid/variety. Also by } \\
\text { altering the grain composition with desired parameters may prove to be more effective in } \\
\text { controlling the development of rancidity. }\end{array}$} \\
\hline Keywords & \\
\hline & \\
\hline Article Info & \\
\hline & \\
\hline & \\
\hline
\end{tabular}

\section{Introduction}

Pearlmillet is a multi-purpose cereal crop providing food, fodder and fuel worldwide (Jalaja et al., 2016). It is cultivated mainly in arid and semi-arid regions of West Africa, East Africa and many parts of India, where it constitutes upto $75 \%$ of total cereal production, hence represents an important part of local diets (Oumar et al., 2008). It is one of the most drought resistant grains in commercial production due to its ability to grow in dry weather either in vegetative or reproductive phase (Lestienne et al., 2005).
With its deep rooted nature it effectively uses residual nitrogen, phosphorous and potassium and hence survives in infertile soils and high temperatures, in excess of $40^{\circ} \mathrm{C}$. These characteristics enhance pearl millet's desirability in lower input, dryland production systems. Pearl millet has a potential to contribute food and nutritional security of the country as it is a powerhouse of nutrients, a climate-resilient crop and possess unique nutritional characteristics.

In India, pearl millet is a third most important crop grown after rice and wheat. It is grown 
on 7.12 million ha area during 2015-16. The major pearl millet growing states are Rajasthan, Maharashtra, Gujarat, Uttar Pradesh and Haryana, accounts for 90\% acreage in the country. Mostly it is cultivated in Kharif season.

\section{Nutritional value of pearlmillet}

Pearl millet is one of the four most important cereals (rice, maize, sorghum and millets) grown in the tropics. It is highly nutritious and contains high amounts of fiber, vitamins and minerals. Recently, millets have been recognized by Government of India as 'Nutri Cereal'. It is high in energy with calorific value of $361 \mathrm{Kcal} / 100 \mathrm{~g}$ and high in fibre content $(1.2 \mathrm{~g} / 100 \mathrm{~g})$. The protein has low prolamin fraction which makes it gluten free and it keeps its alkaline nature after cooking also, hence ideal as food for gluten intolerance people. Pearl millet is also rich source of vitamins and minerals. It is a good source of vitamin-B, Vitamin-A, folic acid, calcium and magnesium. It is rich in iron and zinc with 8 times higher iron content than rice and high amount of antioxidants which may be beneficial for the overall health and wellbeing. In spite of several health and economic benefits, millets are disappearing from the people's diet and farm lands.

\section{Health benefits of pearlmillet}

Pearl millet is a good source of carbohydrates, protein and fiber.

Bajra is rich in insoluble fibre that helps in digestion. This insoluble fibre increases the intestinal transit time and also reduces the secretion of bile juices. Thus lowers the risk of gallstone formation.

Pearl millet consumption control diabetes. It has very low Glycaemic index (GI). Management of diabetes involves the reduction of postprandial hyperglycaemia and good glycaemic control. It tends to digest slowly and release glucose at a slower rate as compared to other foods. This helps in maintaining healthy blood sugar levels for a long period of time (Chandrasekara and Shahidi, 2011).

It is very good for weight loss. Being high in fibre content, it takes longer time to move from the stomach to the intestines and in turn curbs hunger for a long span of time.

Pearl millet has anti-cancer properties. A study showed that regular intake of bajra protects pre-menopausal women from developing breast cancer.

Pearl millet grain contains phenolic compound especially flavanoids, in pericarp and testa of a grain, which inhibit tumor development (Huang and Ferraro, 1992).

It contains essential amino acid, methionine; B-complex vitamins (niacin, thiamine and riboflavin); high iron, zinc, potassium and magnesium.

Niacin reduces cholesterol while magnesium is essential for maintaining good heart health, as it lowers blood pressure and reduces the risk of heart attacks.

Reduces cholesterol: It contains phyto chemical, which is called phytic acid believed to increase cholesterol metabolism. It also stabilises the level of cholesterol in the body.

Pearl millet is a gluten free cereal which is very beneficial in gluten intolerance or celiac disease. In place of wheat, barley and ryebased foods, person with celiac disease should intake gluten-free diet.

In the developed countries there is a growing demand for gluten-free foods and beverages. 
Problems associated with less shelf life Rancidity

Pearl millet is a nutrient dense crop, however its full potential is not exploited due to rancidity and off odour during storage of flour and its products, thus reducing its marketability and making it less profitable. The term 'rancidity' is used for unpleasant odours and flavours in foods resulting from degradation in the fat content. Oxidation of fats is caused by a biochemical reaction between fats and oxygen. In this process the long-chain fatty acids are degraded and shortchain compounds are formed. In Pearl millet crop, its grain is small $(3-15 \mathrm{mg})$ but has a proportionally larger germ than all other cereal grains, except perhaps maize (Taylor, 2004). It has $74 \%$ unsaturated fatty acids [oleic (C18:1), linoleic (C18:2) and linolenic (C18:3)] and rest saturated fatty acids [stearic acid, palmitic acid]. Attributed to the nature of the fat, flour prepared from this climatechange-ready crop has a low shelf-life. Pearl millet grains contain a higher amount of lipids than any other cereals. High fat content and active lipases are the concern for rancidity. The enzyme lipase is found in the pericarp and shows relatively higher activity in Pearl millet as compared to other cereal grains (Galliard, 1999). Pearl millet flour is thus susceptible to the development of rancidity within a few days due to hydrolytic deesterification of triglycerides and subsequent oxidation of the resulting de-esterified unsaturated fatty acids (Lai and VarrianoMarston, 1980). Apart from hydrolytic enzyme lipase, Pearl millet also contains oxidative enzymes like peroxidases and polyphenol oxidases, which also play role in deterioration of flavor in pearl millet. Hence the pearl millet flour can't be stored for long periods, this becomes the reason for drudgery of women in houses. As the women in villages hand pound the grain daily according to the need. The problem of rancidity hence delimits its use in commercial products. Thus, research is needed to increase shelf life of pearl millet flour.

\section{Mitigation strategies}

To address the problem of rancidity various pre-processing and post processing treatments have been developed and various research have been done. It involves decortication or pearling of grain, where its outer fat layer is removed; defatting of the flour, blanching in boiling water,

Inactivation of enzymes, use of antioxidants to slow down the oxidation of triglycerols, fermentation and malting, with the storage in different packaging material, use of desiccant and storage at low temperature.

However, there's not enough work done in development of genotyes with enhanced shelf life. This area needs to be strengthened as understanding the determinant of rancidity will be its solution. Recently the work has been initiated in ICRISAT (Datta et al., 2016) in determining the variability in pearlmillet germplasm for rancidity profile. Also, in another recent study, genotypic variation is found in pearl millet hybrids, CMS lines, inbred lines and white composites for rancidity indicators viz., fat content, total phenol content, development of FA and activities of POX, LOX and PPO. Among the hybrids, HHB 197 and inbred HBL 11 were found promising for developing low-rancid pearl millet variety or hybrid (Goyal et al., 2017).

A way forward in enhancing demand of Pearlmillet is a need of holistic approach with research on appropriate pre- and post-harvest strategies, processing strategies and marketing strategies with the intervention of government policies. As a big achievement, recently Government of India has put millets like 
jowar and bajra in Public distribution system to improve nutritional security of the poor. The government also declared some millets, which have high nutritive value, 'NutriCereals' for production, consumption and trade point of view.

\section{References}

Chandrasekara, A., Shahidi, F. 2011. Antiproliferative potential and DNA scission inhibitory activity of phenolics from whole millet grains. J Funct Foods, 3, $159-70$.

Datta, M.S., Gupta, S.K., Banerjee, R., Gite, S., Durgalla, P., and Bagade, P. 2016. Determination of variability in rancidity profile of select commercial Pearl millet varieties/hybrids. DC $24 . \quad$ Poster presented in CGIAR Research Program on Dryland Cereals Review Meeting held at Hyderabad, India, 5-6 October 2016. International Crops Research Institute for the Semi-Arid Tropics, Patancheru, Telengana, India.

Galliard, T., 1999. Rancidity in cereal products, in Rancidity in Foods, ed. by Allen JC and Hamilton RJ, Aspen Publishers, Gaithersburg, Maryland, pp. 140-156

Huang, M.J., C. Ho, C.Y. Lee (Eds.), Phenolic Compounds in Food and Their
Effects on Health. II. Antioxidants and Cancer Prevention, American Chemical Society, Washington, DC (1992), pp. 834.

Jalaja, N., Maheshwari, P., Naidu, K. R., and Kavi Kishor, P. B., 2016. In vitro regeneration and optimization of conditions for transformation methods in Pearl millet, Pennisetum glaucum (L.). Int. J. Clin. Biol. Sci. 1, 34-52.

Lai C.C., Varriano-Marston E., 1980. Changes in the pearl millet during storage. Cereal Chemistry 57, 275.

Lestienne, I., Besançon, P., Caporiccio, B., Lullien-Péllerin, V., and Tréche, S. 2005. Iron and zinc in vitro availability in pearl millet flours (Pennisetum glaucum) with varying phytate, tannin, and fiber contents. J. Agric. Food Chem. 53, 3240-3247.

Oumar, I., Mariac, C., Pham, J. L., and Vigouroux, Y. 2008. Phylogeny and origin of pearl millet (Pennisetum glaucum [L.] $\mathrm{R}$. $\mathrm{Br}$ ) as revealed by microsatellite loci. Theor. Appl. Genet. $117,489-497$.

Taylor, J.R.N. 2004. Millet: Pearl, in Encyclopedia of Grain Science, Volume 2, ed. by Wrigley $\mathrm{C}$, Corke $\mathrm{H}$ and Walker CE, Elsevier, London, pp. 253261.

\section{How to cite this article:}

Nirupma Singh, S.P. Singh, Manoj Kumar, Krishan Kanhiya and Arvind Kumar. 2018. Nutri Cereal Pearlmillet: Way Forward. Int.J.Curr.Microbiol.App.Sci. 7(06): 578-581. doi: https://doi.org/10.20546/ijcmas.2018.706.066 